\title{
Evolutionary Ethnobiology. Edited by Ulysses Paulino Albuquerque, Patricia Muniz de Medeiros, and Alejandro Casas. 2015. Springer International Publishing, Cham. 197 pp.
}

Editor's (Felice Wyndham) Note of Correction (August 2021): After publication of the above review, it was brought to our attention that aspects of the framing of the review were found to be objectionable. We have subsequently edited the review to omit the final section which referenced the editors/ authors regional affiliations or possible cultural aspects of scholarship. In particular, the term "scholars of color" was noted as unwelcome in a Latin American context. As editor I should have caught this as a North-Americanist framing that doesn't translate well, for which I apologize. I thank both the review author and the volume authors for bringing this issue into a wider conversation that we can all learn from (see Albuquerque et al.'s Reply and Pierotti's Response, as well as the editorial in Vol 12 No 1: https://doi.org/10.14237/ ebl.12.1.2021).

Raymond Pierotti ${ }^{1 *}$

${ }^{1}$ Department of Ecology and Evolutionary Biology, University of Kansas, Lawrence, USA. *pierotti@ku.edu

Received August 16, 2018

OPEN ठ ACCESS

Accepted October 5, 2018

DOI 10.14237/ebl.9.2.2018.1381

Copyright (C) 2018 by the author(s) licensee Society of Ethnobiology. This is an open-access article distributed under the terms of the Creative Commons Attribution-NonCommercial 4.0 International Public License (https://creativecommons.org/licenses/by-nc/4.0), which permits non-commercial use, distribution, and reproduction in any medium, provided the original author and source are credited.

I am an evolutionary biologist who turned to ethnobiology over 20 years ago, so it was with considerable excitement that I initially received this book on Evolutionary Ethnobiology. This book is promoted by Springer as "the first comprehensive book about evolutionary ethnobiology written in English;" the accuracy of this statement depends on how one defines 'evolutionary' in an ethnobiological context, especially if biological and cultural evolution are conflated to the degree that they are in this book.

One area where this conflation becomes problematic is in the use of the term 'adaptation,' which has different meanings in the two domains. In biological evolution, adaptations are typically considered to be morphological or physiological and result from interaction between an organism's genome and environment. In cultural terms, however, adaptations are almost exclusively behavioral in nature. In both cases, the adaptive feature should allow the organisms with the trait to have greater rates of survival and/or reproduction. In cultural evolution, the adaptation resides not in an individual organism, but in a community, involving potential group selection, creating a conceptual conflict: in biological evolution adaptations are attributes of individuals and cannot be passed or exchanged among individuals. This issue should be important in a book that deals with evolutionary aspects of ethnobiology; however, it is barely addressed, perhaps because many references concerning basic evolutionary ideas are basic evolution texts. Little original research in evolutionary biology is cited, suggesting that many authors are not really conversant with modern approaches to evolution.

This issue is particularly apparent with co-editor Alejandro Casas as lead author in Chapter 3, Evolution of Humans and by Humans, which is primarily a basic review of human evolution of little relevance to ethnobiology. Numerous grammatical errors in this and the following chapter impede appreciation of the material presented, e.g., in Chapter 3 , we read, "but in addition, it has been discussed evidence of bones apparently scratched (?) by tools associated to Australopithecus" (p. 23, emphasis added). We are later told that, "humans select species desirable and undesirable within the system and act in consequence let standing or removing them, respectively" (p. 27). The term 'fire' is used where the word 'burn' is correct, e.g. "people used to fire recurrently forest 
areas" (p. 28). I do not like criticizing writers whose first language is not English; however, I found the lack of grammatical editing unacceptable in a book priced at over $\$ 100$. I do not really blame the authors, but I am surprised at the lack of basic editing and proofreading, which leaves the authors looking less capable than they surely are. Publishers need to edit and proofread, especially when marketing expensive books.

Poor editing is also problematic in Chapter 4, Evolutionary Ecology and Ethnobiology, which could be the core chapter of the book. No major works on evolutionary ecology are cited, only evolution textbooks. Grammatical errors continue as they refer to "vomiting" plants, rather than "vomit-inducing" (p. 39 and Table 4.1). These errors mean that the reader must often stop and reread sentences to figure out meanings, e.g., we are told that "....achievements (of the Green Revolution) have been polemic and motive of extensive discussion" (p. 53, emphasis added).

Another topic of major interest that goes unexamined in this book is the potential for cultural transmission between nonhumans and humans, in which humans observe and copy the dietary or medicinal preferences of other animals. This issue should have been included in the discussion of influences of the environment on natural resource use (Chapter 10), criteria for medicinal plant selection (Chapter 11), use patterns of medicinal plants (Chapter 12), and biological and cultural bases of medicinal and food plants (Chapter 13). Instead, this book concentrates solely on human examples and potential impacts on human evolution, which are often vague and confusing.

Failure to include non-human animal examples limits the usefulness of this volume. Using only plant examples precludes consideration of evolutionary or cultural interactions between humans and other animals. There is no discussion of the roles of hunting or observation in food acquisition and the various authors appear to assume that humans interact almost exclusively with nonmotile lifeforms. For example, in Chapter 13, when discussing human digestive enzymes, we read, "these enzymes played an important role in human adaptation to the chemical environment to which the first hominids were exposed" (p. 179). This leaves the impression that the first hominids were created in situ and had not been evolving for millennia as did other primates — an odd image to present in a book purporting to deal with evolution. It is well established that chimpanzees (Pan paniscus and Pan troglodytes), among numerous other species, can self-medicate (deRoode et al. 2013; Huffman 1997; Shurkin 2014). Several United States tribes indicate that they learn about which plants to use for food or medicine from bears: "In many tribal traditions the bear is recognized as the 'plant gatherer,' bestower of the secrets and mysteries of plants" (Bruchac 2003; Rockwell 1991:6); particularly relevant to the question of how humans made decisions about which plant species to use (Pierotti 2011). In addition, there is evidence from Indigenous peoples around the world that they learned a wide range of skills, including hunting, from wolves (Canis lupus) (Pierotti and Fogg 2017). As a result, discussing how plant knowledge is acquired as involving only humans (or hominids) themselves seems to be a less than complete approach to this complex topic.

Several chapters warrant serious consideration. In particular, Chapter 5 on Evolutionary Approaches to Ethnobiology does an admirable job of explaining how modern phylogenetic approaches can be used to assess data from ethnobiological studies by comparing use patterns of plants among cultures in relation to the evolutionary relationships among the plants themselves. This chapter emphasizes the importance of using approaches from several disciplines to generate novel and unexpected insights. Chapter 6 addresses the use of Niche Construction Theory (NCT) (Odling-Smee et al. 2003) to look at relationships among species, including humans. NCT is based on the discovery that species in ecosystems often modify ecosystem functions in ways that impact the use patterns of other species (e.g., beavers). Ironically, this chapter again focuses solely on humans, even though the concepts behind NCT were developed using non-humans.

Other issues discussed at some length are the relationships and patterns of use between food and medicinal plants (Chapters 10-14). It is argued that medicinal uses probably emerged from plants first used as food, but this seems to ignore the distinction between preventive medicine and treatment of illness or injury. It seems likely that nearly all plant foods are used for purposes of health, although some may only be used to treat ailments. The authors argue that fruits are examples of plant foods not used for medicinal purposes, disregarding the vitamins and anti-oxidizing agents found in many fruits. 
I have not identified specific authors in most comments, as these chapters predominantly have numerous co-authors, averaging more than five authors on twelve of fourteen chapters, rendering it difficult to associate specific ideas with any individual. The editors are among the multiple co-authors, with lead editor Albuquerque co-authoring ten chapters and second editor Medeiros co-authoring seven, all with Albuquerque. Only Chapter 7, on knowledge transmission and cultural evolution is single authored. Chapter 12 has two authors, lead editors Medeiros and Albuquerque. There is an earlier version of this book, published in 2013 in Portuguese as Etnobiologia: Bases Ecologicas e Evolutivas, also edited by Albuquerque, who coauthored seven of its eight chapters. Thus, Albuquerque has generated 19 publications, including the two books themselves as distinct publications, from this enterprise. In consequence, we have a book published by a major press that presents a very narrow perspective on how ethnobiology interacts with evolution.

\section{References Cited}

Bruchac, J. 2003. Our Stories Remembered: American Indian History, Culture, and Values Through Storytelling. Fulcrum Press, Golden, CO. de Roode, J. C., T. Lefèvre, and M. D. Hunter. 2013. Self-Medication in Animals. Science 340:150-151. DOI:10.1126/science.1235824.

Huffman, M. 1997. Current Evidence for Selfmedication in Primates: A Multidisciplinary Perspective. Yearbook Physical Anthropology 104:171200.

Odling-Smee, F. J., K. N. Laland, and M. W. Feldman. 2003. Niche Construction: The Neglected Process in Evolution. Princeton University Press, Princeton, NJ.

Pierotti, R. 2011. Indigenous Knowledge, Ecology and Evolutionary Biology. Routledge, Taylor and Francis Group, New York and Abingdon, United Kingdom.

Pierotti, R., and B. Fogg. 2017. The First Domestication: How Wolves and Humans Co-evolved. Yale University Press, New Haven, CT.

Rockwell, D. 1991. Giving Voice to Bear: North American Indian Rituals, Myths, and Images of the Bear. RobertsRinehart, Niwott, CO.

Shurkin, J. 2014. Animals that Self-medicate. Proceedings of the National Academy of Sciences 111:17339 -17341. DOI:10.1073/pnas.1419966111. 